\title{
Effectiveness of Psychoeducation on Expressed Emotion of Family Members and as Perceived by the Patient with Schizophrenia
}

\author{
Boby Begam ${ }^{1}$, Arunjyoti Baruah ${ }^{2}$
}

\begin{abstract}
Background: Expressed emotion is a measure of the family environment that is based on how the relatives of a psychiatric patient spontaneously talk about the patient. Outcome of the mental disorder depends upon the various prognostic factors. Among various prognostic factors, expressed emotion is the bad prognostic factor, which is the negative attitude shown by a family member toward the patient. This expressed emotion can be reduced and is reversible if the family member and the patient undergo various psychoeducation programs.

Aim: To find out the effectiveness of psychoeducation on expressed emotion of family members and patients with schizophrenia.

Method: The study adopted a quantitative approach with pre-experimental design. Fifty patients with schizophrenia and their family members from Tertiary Hospital of Assam, following convenience sampling technique, were selected. Brief Psychiatric Rating Scale (BPRS) was used to rule out psychopathology in patient. Family Attitude Scale and Family Emotional Involvement and Criticism Scale were used for assessing the expressed emotion of family members and the patient as a pretest and then on the same day psychoeducation was provided. On the 30th day of follow-up, again assessment of expressed emotion was done by using same scales as posttest. Analysis was done by using SPSS version 18. Results: There was a significant difference between the expressed emotion of family members and patients with schizophrenia following psychoeducation. So, psychoeducation was effective to decrease the level of expressed emotion.

Conclusion: Psychoeducation has a positive impact on decreasing the level of expressed emotion and thus improving the outcome of mental illness.

Keywords: Expressed emotion, Patient with schizophrenia, Family member, Psychoeducation.

Eastern Journal of Psychiatry (2020): 10.5005/jp-journals-11001-0009
\end{abstract}

\section{INTRODUCTION}

Mental illness has an impact on various aspects of living. Expressed emotion is the negative behavior shown by the family member toward the patient. ${ }^{1}$ Expressed emotion is concurrent with mental illness and found to have a negative impact on the health of a psychiatric patient as well as whole family. It is the bad prognostic factor for patients with schizophrenia. The components of expressed emotion include hostility, critical comments, and emotional over-involvement. The quantification of critical comments and hostility is greatly reliant on the way in which the respondent uses their tone of voice to convey their feelings while the judgment of over-involvement also takes into account on the basis of reported behavior. Family environment plays a crucial role in influencing the onset, as well as course of mental illness particularly that of schizophrenia and other related psychotic disorders. ${ }^{2}$ Researchers found that relapse rate in high expressed emotion group is much higher than low expressed emotion. Sharif et al. conducted a study and the result showed positive effects in reduction of family burden and patients symptoms immediately 1 month after the intervention. ${ }^{3}$

Research has shown that adequate psychoeducation program about the mental illness and importance of family support can be taught to family members and patients to increase their knowledge and decreased expressed emotion. It will help the patient in reducing the chances of relapse and rehabilitation cycle and to live an independent life. ${ }^{4-6}$

Therefore, it is necessary to assess the prevalence of expressed emotion in the families of mentally ill patients and to teach patients
${ }^{1}$ VKNRL Nursing School, Numaligarh, Golaghat, Assam, India

${ }^{2}$ Department of Psychiatric Nursing, LGBRIMH, Tezpur, Assam, India

Corresponding Author: Arunjyoti Baruah, Department of Psychiatric Nursing, LGBRIMH, Tezpur, Assam, India, Phone: 9854082201, e-mail: arunjyotibaruah@yahoo.co.in

How to cite this article: Begam B, Baruah A. Effectiveness of Psychoeducation on Expressed Emotion of Family Members and as Perceived by the Patient with Schizophrenia. East J Psychiatry 2020;23(1):21-26.

Source of support: Nil

Conflict of interest: None

and family members about the illness and how to take care of themselves while providing care to the patient to avoid expressed emotion toward the patient. So the main aim of conducting this study was to assess the effectiveness of psychoeducation on expressed emotion of family members and patients.

\section{HyPOTHESES}

$\mathbf{H}_{1}$ : There will be a statistically significant difference between expressed emotion of the family member and psychoeducation at 0.05 level of significance.

$\mathrm{H}_{2}$ : There will be a statistically significant difference between expressed emotion as perceived by the patient with schizophrenia and psychoeducation at 0.05 level of significance. 
$\mathrm{H}_{3}$ :There will be a statistically significant association between pretest score of the family member and selected sociodemographical variable at 0.05 level of significance.

$\mathrm{H}_{4}$ : There will be statistically significant association between expressed emotion as perceived by the patient with schizophrenia and selected sociodemographical variable at 0.05 level of significance.

\section{Methodology}

The study adopted a quantitative approach with pre-experimental design. Fifty patients with schizophrenia and their family members from Tertiary Hospital of Assam following convenience sampling technique were selected for checking the effectiveness of psychoeducation on expressed emotion. The study was conducted in the Tertiary Hospital of Assam. Patients of both genders having BPRS rating less than 30 under the age-group 18-55 years with diagnosed case of schizophrenia according to ICD 10 and able to understand Assamese language were selected. Inclusion criterion for the family was staying and providing care to the patient for at least 6 months and attending OPD of Tertiary Hospital of Assam with the patient, and the exclusion criterion was a family member diagnosed with mental illness.

\section{Tools}

Tools used in the present study are:

- Sociodemographic pro forma for patients and family members was made separately.

- Brief Psychiatric Rating Scale (BPRS) ${ }^{7}$ : It is a clinician-rated tool designed to assess change in severity of psychopathology in psychotic illnesses. Items cover the broad range of symptoms (18 items) that are commonly seen in psychotic patients including hallucinations, delusions, disorganizations as well as mood disturbances, e.g., anxiety, hostility, and depression.

- Family Attitude Scale (FAS) ${ }^{8}$ : It offered a very internally consisted measure that was most closely related to the hostility/criticism aspect of Expressed Emotion determination. FAS was been emerging as a reliable, brief measure of anger, burden, or "stress" within a relationship. It is a useful 30-item self-reported measure of expressed emotion, which mainly focuses on criticism and hostility. The items were scored from $0-4$. The responses are $0=$ never, $1=$ very rarely, $2=$ some days, 4 = every day. The FAS had high internal consistency in all the samples. The optimal cut off score is 60 . High FAS indicates high expressed emotion.

- Family Emotional Involvement and Criticism Scale (FEICS) ${ }^{9}$ : It is a self-report scale to measure the expressed emotion. The FEICS has two subscales: perceived criticism (PC) and intensity of emotional over-involvement. The reliability is high with the PC subscales having Cronbach's alpha of 0.82 and the emotional involvement (EI) subscale an overall alpha of 0.74 . The scale consists of 14 items with score ranging from $1-5$. The responses are $1=$ almost never, $2=$ once in a while, 3 = sometimes, $4=$ often, and $5=$ almost always. The present study utilizes FEICS to measure expressed emotion as perceived by the persons with schizophrenia. Total score of the tool is 70 out of which perceived criticism is 35 and intensity of emotional involvement is 35 . Higher score indicates high perceived expressed emotion.

\section{Procedure}

Written informed consent was taken from the subjects prior to application of tools. Brief Psychiatric Rating Scale was used to rule out psychopathology in patients and if the score was less than 30 , then the patients were included in the study. Family Emotional Involvement and Criticism Scale and Family Attitude Scale were used for assessing the expressed emotion of patients and family members as a pretest and then on the same day psychoeducation on expressed emotion was provided to both the patient and the family. On the 30th day of follow-up, again assessment of expressed emotion was done by using same scales as a posttest. Analysis for effectiveness of psychoeducation was done by calculating paired " $t$ " test with the help of SPSS version 18.

\section{Results}

Calculation was done by using both descriptive and inferential statistics with the help of SPSS 18 version, and the result is divided into three part that is sociodemographic, paired " $t$ " test, and association.

The sociodemographic data showed that average age of the family member was 41.56 years and of patient was 33.34 years. Majority of the family members with patients, i.e., $76 \%(f=38)$ reside in rural area with their nuclear families that consist of $60 \%(f=40)$, and $78 \%(f=39)$ were Hindu by religion. Forty-four percent $(f=22)$ were parents of the patients. Sixty percent $(f=30)$ of the family members were married and $32 \%(f=16)$ completed schooling up to middle school and out of which $42 \%(f=21)$ were doing business. Majority of the caregivers, i.e., $88 \%(f=44)$ of them did not attend any psychoeducation program.

Sociodemographic findings of the patient show that $60 \%$ $(f=30)$ of the patients were men out of which $52 \%(f=26)$ were married. Most of them completed their schooling up to middle school, i.e., $38 \%(f=19)$ and working as homemaker, i.e., $28 \%(f=14)$. Majority, that is, $74 \%(f=37)$, did not attend any psychoeducation program. Fifty-four percent of $(f=27)$ the patients were going for regular follow-up and $50 \%(f=25)$ of the patients were taking medication regularly.

The data presented in the Table 1 show mean and the standard deviation of pretest score and posttest score of family members to be $42.2 \pm 18.002$ and $39.20 \pm 17$, respectively with calculated paired " $t$ " test value of 8.25 (40) which is greater than the tabulated " $t$ " value of 2.02 at 0.05 level of significance. Thus the null hypothesis is rejected and alternative hypothesis is accepted at the level of significance of 0.05 . Thus it can be stated that there is a significant difference between pretest and posttest score of family members following psychoeducation.

The data presented in the Table 2 show that mean and the standard deviation of pretest score and posttest score of persons with schizophrenia were $40.17 \pm 18.002$ and $37.17 \pm 6.7$, respectively

Table 1: Mean, standard deviation, and paired " $t$ " test values of pretest and posttest of family members $(n=41)$

\begin{tabular}{lcccc}
\hline \multicolumn{5}{c}{ Family members of patients with schizophrenia } \\
\hline Parameters & Mean & SD & " $t$ " & $\begin{array}{c}p \\
\text { (value) }\end{array}$ \\
\hline Pretest score & 42.2 & 8.002 & $8.25(40)$ & 0.000 \\
Posttest score & 39.20 & 17 & & \\
\hline
\end{tabular}

Tabulated " $t$ " value is 2.02. Significant at the 0.05 level 
with calculated paired " $t$ " test value of 11.9 (40) which is greater than the tabulated " $t$ " value 2.02 at 0.05 level of significance. Thus the null hypothesis is rejected and alternative hypothesis is accepted at the level of 0.05 significance. Thus it can be inferred that there is a significant difference between pretest and posttest score of family members following psychoeducation.

The data presented in the Table 3 show that there is no significant association between selected sociodemographic variables of family members of patients with schizophrenia and pretest score except in terms of domicile which is found to be

Table 2: Mean, standard deviation, and paired " $t$ " test value of pretest and posttest score of the patients $(n=41)$

\begin{tabular}{lcccc}
\hline \multicolumn{5}{c}{ Patients with schizophrenia } \\
\hline Parameters & Mean & $S D$ & ${ }^{\prime \prime}(d f)$ & $p$ (value) \\
\hline Pretest score & 40.17 & 6.7 & $11.9(40)$ & 0.000 \\
Posttest score & 37.95 & 6.9 & & \\
\hline
\end{tabular}

Tabulated " $t$ " value is 2.02 Significant at the 0.05 level significant. Hence, the alternative hypothesis $\left(\mathrm{H}_{4}\right)$ is rejected and null hypothesis $\left(\mathrm{H}_{04}\right)$ is accepted at 0.05 level of significance.

The data presented in Table 4 show that there is no significant association between selected sociodemographic variables and pretest score of persons with schizophrenia. Hence, the alternative hypothesis $\left(\mathrm{H}_{4}\right)$ is rejected and null hypothesis $\left(\mathrm{H}_{04}\right)$ is accepted at 0.05 level of significance.

\section{Discussion}

It is divided into three sections according to the objective of study.

\section{Section I}

\section{For Family Members}

In the present study, it was found that mean age of the family member with standard deviation is $41.56 \pm 14.572$. According to the 2011 census report, $62.5 \%$ of the population belong to 15-59 years, and this may be the reason for mean age-group belonging to middle age-group. Findings of the present study

Table 3: Chi-square test $\left(x^{2}\right)$ between pretest of family members with selected sociodemographical variable $(n=50)$

\begin{tabular}{|c|c|c|c|c|c|c|c|}
\hline \multirow[b]{2}{*}{ Sociodemographic variables } & \multirow[b]{2}{*}{ Categories } & \multicolumn{2}{|c|}{ Expressed emotion } & \multirow{2}{*}{$\begin{array}{c}\text { Calculated } \\
x^{2}\end{array}$} & \multirow[b]{2}{*}{$d f$} & \multirow[b]{2}{*}{$p$} & \multirow[b]{2}{*}{ S/NS } \\
\hline & & $>42$ & $\leq 42$ & & & & \\
\hline Gender & $\begin{array}{l}\text { Male } \\
\text { Female }\end{array}$ & $\begin{array}{l}10 \\
16\end{array}$ & $\begin{array}{r}18 \\
6\end{array}$ & 6.762 & 1 & 0.28 & NS \\
\hline Religion & $\begin{array}{l}\text { Hindu } \\
\text { Others }\end{array}$ & $\begin{array}{r}21 \\
5\end{array}$ & $\begin{array}{r}20 \\
4\end{array}$ & 0.056 & 1 & 0.948 & NS \\
\hline Marital status & $\begin{array}{l}\text { With spouse } \\
\text { Without spouse }\end{array}$ & $\begin{array}{r}17 \\
9\end{array}$ & $\begin{array}{l}14 \\
10\end{array}$ & 0.263 & 1 & 0.608 & NS \\
\hline Educational status & $\begin{array}{l}\text { Below primary } \\
\text { Above primary }\end{array}$ & $\begin{array}{r}6 \\
20\end{array}$ & $\begin{array}{r}3 \\
21\end{array}$ & 0.946 & 1 & 0.467 & NS \\
\hline Domicile & $\begin{array}{l}\text { Rural } \\
\text { Urban }\end{array}$ & $\begin{array}{r}19 \\
7\end{array}$ & $\begin{array}{r}7 \\
17\end{array}$ & 9.641 & 1 & 0.004 & $\mathrm{~S}$ \\
\hline Relationship with patient & $\begin{array}{l}\text { Parents } \\
\text { Others }\end{array}$ & $\begin{array}{l}15 \\
11\end{array}$ & $\begin{array}{r}8 \\
16\end{array}$ & 0.084 & 1 & 0.161 & NS \\
\hline Attended psychoeducation & $\begin{array}{l}\text { Yes } \\
\text { No }\end{array}$ & $\begin{array}{r}3 \\
23\end{array}$ & $\begin{array}{r}3 \\
21\end{array}$ & 0.011 & 1 & 1.000 & NS \\
\hline
\end{tabular}

S = significant; NS = not significant

(Cells have expected counts less than 5, Fisher's exact was considered as the " $p$ " value)

Table 4: Chi-square test $\left(\mathrm{x}^{2}\right)$ between pretest of persons with schizophrenia and selected sociodemographic variable $(\mathrm{n}=50)$

\begin{tabular}{|c|c|c|c|c|c|c|c|}
\hline \multirow[b]{2}{*}{ Sociodemographic variables } & \multirow[b]{2}{*}{ Categories } & \multicolumn{2}{|c|}{ Expressed emotion } & \multirow{2}{*}{$\begin{array}{c}\text { Calculated } \\
x^{2}\end{array}$} & \multirow[b]{2}{*}{$d f$} & \multirow{2}{*}{$\begin{array}{c}p \\
\text { Value }\end{array}$} & \multirow[b]{2}{*}{ S/NS } \\
\hline & & $<40$ & $\leq 40$ & & & & \\
\hline \multirow[t]{2}{*}{ Gender } & Male & 15 & 15 & 3.125 & 1 & 0.040 & NS \\
\hline & Female & 5 & 15 & & & & \\
\hline \multirow[t]{2}{*}{ Marital status } & Married & 9 & 17 & 0.65 & 1 & 0.565 & NS \\
\hline & Others & 11 & 13 & & & & \\
\hline \multirow[t]{2}{*}{ Religion } & Hindu & 15 & 26 & 1.107 & 1 & 0.545 & NS \\
\hline & Others & 5 & 4 & & & & \\
\hline \multirow[t]{2}{*}{ Domicile } & Rural & 9 & 17 & 0.654 & 1 & 0.565 & NS \\
\hline & Urban & 11 & 13 & & & & \\
\hline \multirow[t]{2}{*}{ Attended psychoeducation } & Yes & 3 & 10 & 2.096 & 1 & 0.565 & NS \\
\hline & No & 17 & 20 & & & & \\
\hline \multirow[t]{2}{*}{ Follow- up } & Regular & 11 & 16 & 0.13 & 1 & 1.000 & NS \\
\hline & Irregular & 9 & 14 & & & & \\
\hline \multirow[t]{2}{*}{ Medications status } & Regular & 10 & 15 & .019 & 1 & 1.000 & NS \\
\hline & Irregular & 10 & 15 & & & & \\
\hline
\end{tabular}

$\mathrm{S}=$ significant; NS = not significant

(Cells have expected counts less than 5, Fisher's exact was considered as the " $p$ "value) 
are supported by the study conducted by Nirmala et al. ${ }^{6}$ in which it was found that mean age of the caregivers was $47.3 \pm 13.2$ years. Studies conducted by Batra et al. ${ }^{10}$ (42. 07 years) and Carra et al. ${ }^{11}$ ( $m=54.7$ years; $\mathrm{SD}=10.5$ ) showed that most of the key relatives were middle aged, which support the present study.

In the present study, it was found that $58 \%(f=29)$ of the family members were men and $42 \%(f=21)$ were women. In the Indian society, women are mostly confined to household activity. It may be one of the reason for less number of female caregiver accompanying their relatives to treatment centers. A study conducted by Nirmala et al. $^{6}$ showed that $51.4 \%$ of the caregivers were men, which supports the findings of present study. A study conducted by Batra et al. ${ }^{10}$ showed that majority of the caregivers $(65 \%)$ were women, which is contrasting with the present study results.

In the present study, it was found that the family members, i.e., $60 \%(f=30)$ were married, $36 \%(f=18)$ were unmarried, and $2 \%(f=1)$ were divorced and $2 \%(f=1)$ were separated. A study conducted by Batra et al. ${ }^{10}(65 \%)$ found that majority of the caregivers were married, which is similar to the present study. A study conducted by Bernard et al. found that (26\%) of subjects were married and the rest (74\%) were single, which is in contrast with the present study.

In the present study, it was found that majority of the family members, that is, $78 \%(f=39)$ were Hindus, $14 \%(f=7)$ were Muslims, and $8 \%(f=4)$ were Christians. In India, according to 2011 census, the population of Hinduism is $79.8 \%$, and this might be the reason of more Hindu population. Studies conducted by Nirmala et al. ${ }^{6}$ $(80 \%)$ and Batra et al. $^{10}(82 \%)$ found that majority of the patients belonged to Hindu religion, which is similar to the present study.

In the present study, majority of the sample in the family members studied up to middle school, i.e., $32 \%(f=16), 26 \%(f=13)$ completed their graduation, $22 \%(f=11)$ completed their high school, 11\% ( $f=22)$ completed their higher secondary, and 2\% $(f=1)$ were illiterate. In India mainly in the rural area because of poverty and low socioeconomic status, people are not giving importance to education, and this may be the possible reason for only middle-level education. A study conducted by Carra et al. ${ }^{11}$ showed that most of the key relatives have completed their study up to middle class, which upports the present study.

In the present study, i.e., $42 \%(f=21)$ of the family members were business people, $20 \%(f=10)$ were homemakers, $20 \%(f=10)$ were cultivators, $6 \%(f=3)$ were doing government service, $4 \%(f=2)$ were private employees, $4.9 \%(f=2)$ were daily wage earners, and $4 \%(f=2)$ were unemployed.

In the present study, the mean income with standard deviation of the family member was $10280.0 \pm 9856.190$. A study conducted by Batra et al. ${ }^{10}$ found that majority of the caregivers were from lower middle-income group, which is similar to the present study.

In the present study, $76 \%$ ( $f=38$ ) of the family members reside in rural area and $24 \%(f=12)$ reside in urban area. According to 2011 census, majority (69\%) of the Indian population (i.e., 700 million people) lived in rural areas and $31 \%$ of the population lived in the urban areas. A study conducted by Batra et al. ${ }^{10}$ found that majority of the caregivers (52\%) were from urban areas which is in contrast with present study result.

In the present study, majority of the family members, i.e., $60 \%(f=30)$ belong to nuclear family and $40 \%(f=20)$ belong to joint family. It may be possible because of the increased urbanization and due to demographic shift there are more nuclear families. Studies conducted by Sadiq and Suhail ${ }^{12}(75 \%)$ and Batra et al. ${ }^{10}$
$(60 \%)$ showed that majority of the family members belonged to nuclear family, which support the present study.

In the present study, it was found that family members, i.e., 44\% $(f=22)$ were parents, $18 \%(f=9)$ were siblings, $18 \%(f=9)$ were children, $10 \%(f=5)$ were spouse, and $10 \%(f=5)$ were others in relationship. Parents are considered to be the most caring person for their children in the present scenario of India, and this may be the possible reason for these findings. A study conducted by Carra et al. ${ }^{11}(79 \%)$ and Nirmala et al. ${ }^{6}(48.6 \%)$ showed that majority of the relatives were parents; this finding support the present study.

In the present study, it was found that majority of the sample, that is $88 \%(f=44)$ did not attend any psychoeducation program and $12 \%(f=6)$ attended psychoeducation before. Psychoeducation is mainly provided in the morning time; these can be one of the reason that sample has not attended any psychoeducation in the morning at LGBRIMH.

In the present study, it was found that mean duration of staying with the patient with standard deviation were $14.42 \pm 8.573$. The possible reason may be in the present study as most of the family members were parents so they are staying with patients for a long period of time.

In the present study, it was found that mean duration of giving care with standard deviation was $5.10 \pm 3.382$.. A study conducted by Nirmala et al. ${ }^{6}$ showed that duration of caregiving was $5.9 \pm 3.6$ which is similar to the present study.

In the present study, it was found that majority of the samples, i.e., $96 \%(f=48)$, do not have any other family members having mental illness and $4 \%(f=2)$ of the sample have family members with mental illness. As the literature says, chances of genetic transmission of psychiatric disorder account for only few percentages, and this might be the reason for family members not having mental illness.

In the present study, the findings showed that $78 \%(f=39)$ of the caregivers do not have any illness, $18 \%(f=5)$ were having physical illness, and 4\% (2) were having mental illness. As the literature says, chances of genetic transmission of psychiatric disorder account for only few percentages, and this might be the reason for family members not having mental illness.

In the present study, it was found that mean hours of daily contact with standard deviation were $2.70 \pm 1.403$. Every family member has their own life and work, and this might be the reason of spending only few hours with patients.

\section{For Patients}

In the present study, the mean age of the patient with standard deviation is $32.34 \pm 9.593$. Studies conducted by Nirmala et al. ${ }^{6}$ (33.5 \pm 8.5 years) and Batra et al. ${ }^{10}$ (33.29 years) showed that mean age of the patients is supporting the present study results. A study conducted by Carra et al. ${ }^{11}$ showed that the overall mean age of patients was 29.8 years, which is contrasting with the present study.

The present study finding shows that $60 \%(f=30)$ of the patients were men and $40 \%(f=20)$ were women. Marom et al. ${ }^{13}$ conducted a study where the findings showed that the male was $56.5 \%$ and female was $43.5 \%$, and this finding supports the present study results. A study conducted by Batra et al. ${ }^{10}$ showed that majority of the patients (51\%) were women, which is contrasting with the present study.

In the present study, $52 \%(f=26)$ of the patients were married, $34 \%(f=17)$ were unmarried, $8 \%(f=4)$ were divorced, and $6 \%(f=3)$ were separated. Nirmala et al. $^{6}$ conducted a study and found that $51.4 \%$ were married, which support the present study findings. A study conducted by Batra et al. ${ }^{10}$ showed that majority of the 
patients (51\%) were women which is contrasting with the present study findings.

In the present study, majority of the patients were Hindus by religion, that is, $78 \%(f=39), 14 \%(f=7)$ were Muslims, and $8 \%(f=4)$ were Christians by religion. In India, Hinduism is mostly followed so this may be the possible reason for majority of family members belonging to Hindu religion. Studies conducted by Nirmala et al. ${ }^{6}(80 \%)$ and Batra et al. ${ }^{10}(52 \%)$ found that majority of the patients belong to Hindu religion, which support the present study.

In the present study, majority of the patients, i.e., $28 \%(f=14)$ were homemakers, $12 \%(f=6)$ were cultivators, $24 \%(f=12)$ were businesspeople, $4 \%(f=2)$ were doing government service, $8 \%(f=4)$ were daily wage earners, $20 \%(f=10)$ were unemployed, and $4 \%(f=2)$ were private employees. A study conducted by Carra et al. ${ }^{11}$ showed that employment status was 24/101 which is supporting the present study.

In the present study, it was found that the mean income with standard deviation was $2740 \pm 5106.259$. The reasons for less income might be that the patients are not much educated and involve in cultivation .

In the present study, it was found that $76 \%(f=38)$ of the patients reside in rural area and $24 \%(f=12)$ reside in urban area. A study conducted by Batra et al. ${ }^{10}$ showed that majority of the patients (52\%) were from urban areas which is contrasting with the present study results. Most of the patients who come to OPD of LGBRIMH were from rural area; this might also be the reason.

In the present study, it was found that $60 \%(f=30)$ of the patients belong to nuclear family and $40 \%(f=20)$ belong to joint family. Increased modernization and desire for personal space may be the possible reasons of majority nuclear family. Studies conducted by Sadiq and Suhail ${ }^{12}(75 \%)$ and Batra et al. ${ }^{10}(60 \%)$ found that majority of the patients were from nuclear family, which is similar to the present study.

In the present study, it was found that majority of the sample, that is $74 \%(f=37)$ did not attend any psychoeducation program and $26 \%(f=13)$ attended psychoeducation before. Psychoeducation in the OPD is provided at morning time and the patients are residing at distance so they cannot reach early in the morning. So it might be the reason for not attending psychoeducation.

In the present study, mean duration of illness and duration of treatment were 1, 2, 3, 4 months respectively.

In the study the mean number of admissions were 1, 2, 3, 4 . As most of the patients were brought by their parents and were on supervised treatment, this might be reflected in less number of admissions.

In the present study, 54\% ( $f=27$ ) of the patients were going for regular follow-up and $46 \%$ ( $f=23$ ) were not going for regular follow-up. Nowadays people are aware of mental illness, and they know the importance of follow-up, so this may be the possible reason for present findings.

In the present study, patients showed that $50 \%(f=25)$ were having medication on a regular basis and $50 \%(f=25)$ of them were having medication on irregular basis. Nowadays people are aware of mental illness and they know the importance of medication for mental illness, so this may be the possible reason for present findings.

In the present study, mean value with standard deviation of relapse is $0.10 \pm 463$. As the major number of family member were parents, coming for regular follow-up and taking regular medication so this might be the reason for less number of relapse.

\section{Section II}

To prove the hypothesis $\left(\mathrm{H}_{1}\right.$ and $\left.\mathrm{H}_{2}\right)$ paired " $t$ " test had been computed between the pretest and posttest score of both family members and patient with schizophrenia.

\section{For Family Members}

It was observed that calculated paired ' $t$ ' value for family is 8.25 (40), which is greater than the tabulated " $t$ " value of 2.02 at 0.05 level of significance for family member. Thus the null hypothesis is rejected and research hypothesis is accepted at 0.05 level of significance. Thus it can be inferred that there is a significant difference between pretest score and posttest score of the expressed emotion of family member following psychoeducation. A study conducted by Raghunathan et al. revealed that structured psychoeducation was effective for reducing the expressed emotion of family members of patients with major mental disorder.

\section{For Patients}

It was observed that calculated paired " $t$ " value in patients is $11.9(40)$ which is greater than the tabulated " $t$ " value 2.02 at 0.05 level of significance for patients. Thus the null hypothesis is rejected and alternate hypothesis is accepted at 0.05 level of significance. The results revealed that psychoeducation was effective for reducing the expressed emotion of patients with schizophrenia. Devaramane et al. ${ }^{14}$ conducted a study and found that there was a significant improvement between baseline and the final 3-month follow-up on measures of psychopathology for the patients, as well as family functioning for the caregivers and patients. Sharif et al. ${ }^{3}$ conducted a study on an improvement in most aspects of the BPRS in the patients they took care of. As a result of the intervention, family members may have learned to understand effective ways of expressing emotions in the family context. Moxon and Ronan ${ }^{15}$ conducted a study and found changes in total Expressed Emotion scores improved after treatment by more than twice the magnitude compared to the control condition.

\section{Section III}

To prove the hypothesis $\mathrm{H}_{3}$ and $\mathrm{H}_{4}$, Chi-square test was used. Discussion on the association between pretest score of both family members and patients with selected sociodemographical variable is given below.

\section{For Family Members}

In the present study, it was found that there was no significant association between the gender $\left(x^{2}=6.762, p=0.28\right)$ and pretest score. A study conducted by Carra et al. ${ }^{11}$ showed that the association between the gender of relatives was not significant with level of expressed emotion which is supporting the present study results.

In the present study, it was found that there was no significant association between the selected sociodemographical variable that is religion $\left(x^{2}=0.056, p=0.948\right)$, marital status $\left(x^{2}=0.263, p=0.608\right)$, education $\left(x^{2}=0.946, p=0.487\right)$, and attended psychoeducation $\left(x^{2}=0.011, p=1.000\right)$ with pretest score.

In the present study, it was found that there was a significant association between the domicile and pretest score $\left(x^{2}=9.641\right.$, $p=0.004)$.

In the present study, it was found that there was no significant association between the relationship with the patient and pretest score $\left(x^{2}=0.084, p=0.161\right)$. A study conducted by Carra 
et al. ${ }^{11}$ showed that the association between the relationship with the patient was not significant with level of expressed emotion level which is supporting the present study results.

\section{For Patients}

In the present study, it was found that there was no significant association between the gender and pretest score $\left(x^{2}=3.125\right.$, $p=0.040$ ). A study conducted by Carra et al. ${ }^{11}$ showed that the association between the gender of patients was not significant with the level of expressed emotion level which is supporting the present study results.

In the present study, it was found that there was no significant association between the marital status and pretest score $\left(x^{2}=0.654\right.$, $p=0.565)$. A study conducted by Carra et al. ${ }^{11}$ showed that the association between the gender of patients was not significant with the level of expressed emotion level which is supporting the present study results.

In the present study, it was found that there was no significant association between the religion $\left(x^{2}=1.107, p=0.454\right)$, domicile $\left(x^{2}\right.$ $=0.654, p=0.565)$, attended psychoeducation $\left(x^{2}=2.096, p=0.148\right)$, follow-up $\left(x^{2}=0.13, p=1.000\right)$, and medication status $\left(x^{2}=0.019, p\right.$ $=1.000)$ with pretest score.

\section{Limitations of the Study}

- Nine patients were lost to follow-up.

- Association could not be calculated for some of the sociodemographic variables as the sample size was small.

\section{Conclusion}

The present study was conducted to find out the effectiveness of psychoeducation module on expressed emotion of family members and patients with schizophrenia. Through the present study, after analysis of data it was found that level of expressed emotion was reduced after providing psychoeducation to the subjects. Thus this showed that psychoeducation on expressed emotion was effective in decreasing the level of expressed emotion. It also helped to change the view of patients and family members toward each other and illness. It has taught the responsibility of persons with schizophrenia and the family members for the good outcome of psychiatric disorder. It also suggests that it does not only decrease the level of expressed emotion, but it can also decrease the burden of mental illness across the globe.

\section{References}

1. Leff J, Guilford CV. Expressed Emotion in Families: Its Significance for Mental Illness. Psychiatric Services. 1985; 37:741-742. DOI: 10.1176/ ps.37.7.741-a

2. Amaresha AC, Venkatasubramanian G. Expressed Emotion in Schizophrenia. Journal of Psychological Medicin. 2012;34:12-20. DOI: 10.4103/0253-7176.96149

3. Sharif F, Shaygan M, Mani A. Effect of a psycho-educational intervention for family members on caregiver burdens and psychiatric symptoms in patients with schizophrenia in Shiraz, Iran. BMC Psychiatr. 2012;12(1):1-9. DOI: 10.1186/1471-244X-12-48

4. Ikram A, Suhail K,Jafery SZ, et al. Rates of expressed emotions in Pakistani relatives of patient with schizophrenia. Isr J Psychiatry Relat Sci 2011;48:74-81.

5. Tanaka S, Mino $Y$, Inoue S. Expressed emotion and the course of schizophrenia in Japan. Br J Psychiatry 1995;167(6):794-798. DOI: 10.1192/bjp.167.6.794

6. Nirmala BP, Vranda MN, Reddy S. Expressed emotion and caregiver burden in patients with schizophrenia. J Psychiatr Res 2011; 33(2):119-122. DOI: 10.4103/0253-7176.92052

7. Overall JE, Gorham DR. The brief psychiatric rating scale. Psychol Rep. 1962;(3):799-812. DOI: 10.2466/pr0.1962.10.3.799

8. Kavanagh DJ, O'Halloran P, Manicavasagar V, et al. The family attitude scale: reliability and validity of a new scale for measuring the emotional climate of families. Psychiatry Res 1997;70(3):185-195. DOI: 10.1016/s0165-1781(97)00033-4

9. Shields CG, Franks P, Harp JJ, et al. Development of the family emotional involement and critcism scale (FEICS): a self-report scale to measure expressed emotion. J Marital Fam Ther 1992;18(4):395-407. DOI: 10.1111/j.1752-0606.1992.tb00953.x

10. Batra BS, Ghildiyal R, Saoji AM. Expressed emotions among caregivers of patients with mental illness: a descriptive study. J Dent Med Sci 2016;15:59-68. DOI: 10.9790/0853-1507125968

11. Carra G, Montomoli C, Clerici M, et al. Family interventions for schizophrenia in Italy: randomized controlled trial. Eur Arch Psychiatry Clin Neurosci 2007;257(1):23-30. DOI: 10.1007/s00406-006-0677-z

12. Sadiq S, Suhail K. Relationship of expressed emotion with burden of care and health of caregivers of patients with Schizophrenia. Pak J Soc Clin Psychol 2013;11:3-10.

13. Marom S, Munitz $\mathrm{H}$, Jones $\mathrm{PB}$, et al. Expressed emotion: relevance to rehospitalization in schizophrenia over 7 years. Schizophr Bull 2005; 31(3):751-758. DOI: 10.1093/schbul/sbi016

14. Devaramane V, Pai NB, Vella SL. The effect of a brief family intervention on primary carer's functioning and their schizophrenic relatives levels of psychopathology in India. Asian J Psychiatr. 2011;4(3):183-187. DOI: 10.1016/j.ajp.2011.06.004

15. Moxon A, Ronan K. Providing information to relatives and patients about expressed emotion and schizophrenia in a community-support setting: a randomized, controlled trial. Clin Schizophr RelatPsychoses 2008;2(1):47-58. 